\title{
ALFABETIZAĈ̃O DE JOVENS E ADULTOS: OS DESAFIOS E AS POSSIBILIDADES NA FORMAÇÃO DE EDUCADORES
}

\author{
YOUTH AND ADULT LITERACY: CHALLENGES AND \\ POSSIBILITIES IN TEACHER EDUCATION
}

Jaqueline Luzia da Silva*

Resumo: Este trabalho tem como objetivo apresentar e analisar um curso de extensão para professores, no âmbito do Projeto de Extensão "Desafios e Possibilidades Atuais na Alfabetização de Jovens e Adultos", da Universidade do Estado do Rio de Janeiro (UERJ), que tem por objetivo investir na formação continuada de educadores. A metodologia se constitui em encontros com os professores envolvidos, a partir de temas e reflexões concernentes com os desafios emergentes da prática pedagógica, no sentido de contribuir para pensar sobre a escola oferecida a estes sujeitos. O referencial teórico baseia-se em estudos de autores como Freire (1998; 2002), Arroyo (2006), Soares (2008), entre outros. Os resultados finais apontam que a formação continuada de alfabetizadores vai ao encontro de uma necessidade atual, pois possibilita o repensar de práticas pedagógicas, a partir do diálogo com a realidade, das especificidades dos sujeitos atendidos e de suas necessidades de aprendizagem.

Palavras chave: Alfabetização de jovens e adultos; formação de educadores; práticas pedagógicas.

\begin{abstract}
This study aims to present and analyze an outreach course offered to teachers from the Education of Youth and Adult Program in the scope of the "Current Challenges and Possibilities in Youth and Adult Literacy" from the University of the State of Rio de Janeiro (UERJ). This programme aims to invest in teachers' continuous education. The methodology consisted in meetings with the teachers to discuss and reflect about themes concerning the challenges that emerge from their pedagogical practice, in order to think about the kind of school offered to these subjects. The theoretical reference is based on studies of authors such as Freire (1998; 2002), Arroyo (2006), Soares (2008) among others. The results demonstrate that continuous education of literacy teachers meets a current need as it enables to rethink pedagogical practices based on the dialogue with reality, on the specificity of the population and on their learning needs.
\end{abstract}

Keywords: Youth and adults literacy; teacher education; pedagogical practices. 


\section{Introdução}

Este artigo apresenta e analisa um curso de extensão para professores do Programa de Educação de Jovens e Adultos (PEJA[ PEJA é o Programa de Educação de Jovens e Adultos da Secretaria Municipal de Educação do Rio de Janeiro. ]), no âmbito do Projeto de Extensão intitulado "Desafios e Possibilidades Atuais na Alfabetização de Jovens e Adultos", da Universidade do Estado do Rio de Janeiro (UERJ). Este curso tem por objetivo investir na formação continuada de educadores que trabalham com a alfabetização de jovens e adultos, a partir de temas e reflexões concernentes com os desafios emergentes da prática pedagógica, no sentido de contribuir para pensar sobre a escola oferecida aos jovens e adultos, bem como para mostrar caminhos de atuação trilhados pelas escolas.

Refletir sobre a Educação de Jovens e Adultos (EJA) e mais especificamente sobre a alfabetização requer que sejam considerados alguns dados atuais e extremamente relevantes, que são os índices de analfabetismo da população brasileira acima de 15 anos. Atualmente, são cerca de 13 milhões de brasileiros $(8,3 \%)$ e, se forem considerados os chamados analfabetos funcionais, chega-se ao índice de 34 milhões de pessoas $(17,8 \%)$. No estado do Rio de Janeiro, os índices são de 4,3\% de analfabetos, o que corresponde a mais de 600 mil pessoas e $14,1 \%$ de analfabetos funcionais (cerca de 2.240 .000 pessoas), segundo dados da Pesquisa Nacional por Amostra de Domicílios 2013 (IBGE, 2013).

Diante dessa situação, é interessante traçar uma análise sobre os principais desafios enfrentados pela área educacional no sentido de reverter esse quadro. Mas também se torna importante pensar em algumas possibilidades de atuação diante da realidade brasileira e fluminense que se apresenta, pois "[...] nem todos os analfabetos encontram-se em situação de pobreza, mas as possibilidades tanto de participação dessas pessoas na sociedade quanto de garantia de seus direitos sociais são afetadas pela falta ou pelo pouco estudo" (VÓVIO, 2009, p. 67).

O Programa de Educação de Jovens e Adultos pertence à Rede Municipal de Educação do Rio de Janeiro e tem hoje cerca de 23 mil alunos matriculados, em mais de 130 escolas públicas. Portanto, promover estudos e pesquisas na área tornase muito relevante, principalmente pela inserção em um programa de atendimento para esse público, pela demanda do enfrentamento dos problemas cotidianos e do vislumbramento de alternativas educativas a partir de uma formação sólida, bem elaborada e capaz de servir como instrumento de autorreflexão sobre a prática pedagógica.

No trabalho com a alfabetização de jovens e adultos surgem muitas questões, algumas vezes não respondidas pela própria ação educativa, necessitando de pesquisas e estudos. Entre essas questões, aparecem a evasão e a não aprendizagem dos alunos matriculados na alfabetização de jovens e adultos. Primeiramente, porque a evasão na EJA sempre foi naturalizada. E esta naturalização tem consequências desastrosas, principalmente quando se trata de sujeitos com histórias de vidas diversas, que tiveram direitos negados, limitado acesso à educação escolar e vivências marcadas por uma escolarização que não chegou a alcançar os objetivos esperados (DI PIERRO, 2005). Assim, "processos formativos de educadores e educadoras da EJA passam, obrigatoriamente, por desnaturalizar dos processos escolares a reprovação e a evasão" (ZANETTI, 2008, p. 79), pois são rituais perversos presentes na EJA.

A outra questão - a não aprendizagem - traz um desconforto quando se observa boa parte de alunos nas turmas, matriculados na EJA há dois, quatro, cinco anos no mesmo bloco e que não há esperança, neles e em seus professores, de que sejam aprovados ao final do ano letivo. Isto significa que estar na escola para estes alunos serve muito mais como um modo de socialização do que como oportunidade de realizar aprendizagens significativas almejadas por todos aqueles que retornam à escola na idade adulta.

É impossível negar o esforço público municipal do Rio de Janeiro para ofertar o PEJA, ao longo de três décadas, como parte integrante da Rede Municipal de Educação, com uma estrutura escolar organizada, com recursos materiais, professores concursados e requisitados, direções eleitas pela comunidade escolar, matrículas regulares ao longo do ano letivo e uma estrutura metodológica que procura se adequar aos níveis de aprendizado apresentados pelos alunos.

Entretanto, apesar desta estrutura, ainda permanecem significativas as taxas de evasão dos alunos, que mesmo tendo acesso às matrículas disponibilizadas, não conseguem permanecer na escola. Além disso, os resultados apresentados pelos alunos matriculados nas classes de alfabetização demonstram que nem sempre os objetivos de aprendizagem propostos têm sido alcançados.

É sobre estas questões que se debruça o curso de formação aqui descrito, visando trabalhar com os principais desafios da prática pedagógica da alfabetização de jovens e adultos, tendo em vista que os projetos de extensão das universidades "vêm sobrevivendo e resistindo às intempéries das políticas públicas e neles podemos encontrar "o fazer da EJA" (SOARES, 2008, p. 69). É esse fazer da EJA que tem sido buscado ao longo dos últimos anos, no sentido do reconhecimento da modalidade e pela legitimação do direito à educação para jovens e adultos.

Torna-se interessante compreender as características das escolas com programas oferecidos pelas secretarias de educação, como é o caso do PEJA, pois a EJA ainda apresenta uma inserção marginal no sistema educativo, relegada ao terreno dos programas assistenciais, desenvolvidos por organizações sociais 
que visam atenuar os efeitos perversos da exclusão. $\mathrm{Na}$ avaliação de Haddad e Di Pierro (2000b), há no Brasil uma produção social de analfabetismo, salientada pelas dificuldades de acesso e permanência na escola, pelos altos índices de reprovação e pela imensa pobreza de grande parte da população jovem e adulta. Assim, é importante dar visibilidade às características positivas de escolas e programas públicos de EJA que procuram promover aprendizagens significativas para uma população até então excluída do sistema educacional.

As realidades heterogêneas desafiam os educadores, que precisam aprender a lidar com universos muito distintos, que agregam diversas idades, culturas e expectativas em relação à escola. Assim, o maior desafio da alfabetização na EJA atualmente é o de encontrar caminhos para fazer convergir metodologias e práticas de educação continuada em favor da superação de problemas, como a estreita associação entre as restrições ao acesso à educação e a incidência da pobreza no país, em favor da universalização da alfabetização e da garantia da continuidade e eficácia de programas voltados para a EJA (HADDAD; DI PIERRO, 2000a).

O projeto de extensão "Desafios e possibilidades atuais na Alfabetização de Jovens e Adultos" pretende se constituir como um trabalho de estudo e pesquisa sobre essas questões, com professores e pesquisadores/formadores da área da EJA.

\section{Desafios e possibilidades na alfabetização de jovens e adultos e na formação de educadores}

Entre os principais desafios, verifica-se que a velocidade atual do crescimento da alfabetização é baixa. Assim, torna-se imprescindível que as políticas de Educação de Jovens e Adultos sejam planejadas com o intuito de reverter o quadro de analfabetismo da população com mais de 15 anos de idade. Para isso, é preciso traçar estratégias de acesso, permanência e aprendizagem bem sucedida para os sujeitos matriculados na EJA. Dessa forma, não basta somente a oferta de vagas ou a matrícula, mas é preciso considerar se esses sujeitos estão deixando a condição de não alfabetizados.

Outro desafio a ser enfrentado em relação às políticas educacionais tem a ver com as propostas oferecidas para essas pessoas, pois o que se constata é a pouca eficácia das campanhas de alfabetização de jovens e adultos para resolver o problema do analfabetismo. A efemeridade, o voluntarismo e a precariedade dessas ações não têm garantido os efeitos esperados. Ainda que hoje sejam oferecidos financiamento, livros didáticos e outras condições que motivem os sistemas de ensino no oferecimento da
EJA, a atuação das campanhas pontuais de alfabetização ainda é forte e pouco tem revertido os índices de analfabetismo da população.

Ainda que existam ações voltadas para esse público, as classes de alfabetização não podem se constituir somente como espaços de socialização. Essas escolas necessitam ser espaços - também - de aprendizagem eficaz. O que se constata é que, muitas vezes, a escola da EJA é o melhor dos mundos, educadores e educandos amam estar e conviver nesse espaço, mas os altos índices de retenção/reprovação têm provado que estas escolas não têm garantido a aprendizagem dos sujeitos, que, em consequência, acabam por se evadir da mesma. Essa exclusão educacional produz um elevado contingente de pessoas que, apesar de terem passado pelo sistema de ensino, não conseguiram alfabetizar-se.

Outra questão importante para ser pensada diz respeito à formação inicial dos educadores da EJA, pois, infelizmente, nos cursos de graduação em Pedagogia e nas diversas licenciaturas, pouco (ou nada) se trabalha com as questões metodológicas e de aprendizagem dos sujeitos jovens e adultos. Estas questões, imprescindíveis para o processo educativo, não encontram espaço nos currículos do Ensino Superior em nosso país (SOARES, 2008).

Outro desafio enfrentado é a dificuldade na implementação de programas que sejam adaptados às condições e contextos específicos das comunidades, para que permaneçam na escola, impedindo a evasão e a não aprendizagem. A escola da EJA, muitas vezes, reproduz a escola do ensino regular, voltada para crianças e adolescentes, não considerando as características específicas desta modalidade de ensino.

Um último desafio, porém não menos importante, diz respeito à necessária, mas tão pouco praticada, inserção da EJA nos sistemas escolares sem que se percam suas características específicas advindas da Educação Popular (ARROYO, 2006). Estas características podem estar presentes nas escolas, mas a leitura que se faz é que não há lugar para tais práticas e conhecimentos. Embora a Educação de Jovens e Adultos tenha nascido da Educação Popular, presente nos movimentos sociais e trabalhada por educadores populares, pouco se percebe, nas práticas institucionalizadas, questões como a flexibilização dos currículos, o repensar sobre os espaços e tempos adequados às condições dos sujeitos e uma educação dialógica, crítica e emancipadora, como propõe Freire (1987). Pois quando a EJA penetra o universo escolar, a tendência é enrijecer de tal maneira a educação que ela perde de vista as contribuições dos movimentos sociais que foram fundamentais para sua constituição histórica.

Por outro lado, como possibilidades de trabalho com a alfabetização para jovens e adultos, apresenta-se ainda uma mobilização da sociedade civil, que luta pela alfabetização como meio de emancipação 
e transformação das pessoas e sociedades. Essa luta pela legitimação da EJA ganha espaço por meio da atuação dos Fóruns de EJA, que trazem os educadores para o debate sobre as questões mais relevantes para a área, como as políticas públicas, o financiamento, a formação de educadores etc.

Também aparece em algumas ações de políticas públicas o reconhecimento de que a alfabetização necessita estar vinculada a um processo educativo e não como um fim em si mesma. Para tanto, torna-se necessária a continuidade da escolarização, para além da alfabetização. E também o reconhecimento de que a alfabetização é um processo contínuo e que os sujeitos continuarão aprendendo ao longo da vida, em outros espaços, além da escola.

Os sistemas têm procurado também oferecer ações de formação continuada para os educadores da EJA, no sentido de potencializar o seu trabalho. Essa preocupação também parte dos educadores, que têm se tornado pesquisadores, buscando mais formação, voltando à universidade para continuar seus estudos em cursos de extensão e de pós-graduação lato e stricto sensu.

Além disso, esses próprios educadores têm se empenhado na produção de materiais didáticos articulados à realidade dos sujeitos alfabetizandos. Esses materiais dispensam, muitas vezes, o livro didático ou se articulam ao mesmo no sentido de que haja mais uma ferramenta facilitadora da aprendizagem.

Também se percebe que aparece, nas práticas pedagógicas, um conceito de alfabetização que toma como base o perfil do jovem, do adulto e do idoso, bem como suas necessidades de aprendizagem e as demandas da sociedade. Esse conceito de alfabetização também não prescinde da relação obrigatória e necessária com o conceito de letramento, vistos como processos interdependentes e indissociáveis (SOARES, 2004).

Diante desse quadro, a alfabetização de jovens e adultos não pode ser pensada através de estratégias funcionais, mas como uma política pública, educativa e cultural, diante da qual seja possível reorganizar tempos, espaços e currículos, em que seja possível compartilhar saberes e experiências, garantindo $o$ direito à educação a todos aqueles a quem, no passado, foi negado este direito.

\section{Método}

O objetivo principal do curso de extensão aqui apresentado e analisado se constitui em criar um grupo de estudos e pesquisas na área da alfabetização de jovens e adultos que contribua para o reconhecimento e enfrentamento dos principais desafios da área e para a reflexão sobre a prática dos educadores envolvidos, dando suporte à formação continuada destes sujeitos. Neste sentido, é assumido o que Freire (1998, p. 24) afirma quando diz que "a reflexão crítica sobre a prática se torna uma exigência da relação Teoria/Prática sem a qual a teoria pode ir virando blábláblá e a prática, ativismo".

Assim, é importante que os professores possam repensar sua ação, problematizando-a, para que refaçam sua prática pedagógica e, ao mesmo tempo, revejam as teorias que a embasam e a consolidam. Freire (1998) propõe alinhar e discutir saberes que são fundamentais à prática educativo-crítica ou progressista, para que o educador perceba-se enquanto sujeito da educação, assim como o educando, e que reconheça que ensinar é criar possibilidades para a produção e a construção de conhecimentos e não transferência de conhecimento, no sentido da concepção bancária da educação.

É sobre essa prática educativo-crítica ou progressista que o projeto aqui descrito pretende se debruçar. Para tanto, o grupo promoveu o estudo aprofundado de temas como contextualização histórica, política e social da Educação de Jovens e Adultos; educação inclusiva na alfabetização; relações étnico-raciais; questões didáticas na alfabetização; adolescentes abrigados e em cumprimento de medidas socioeducativas na EJA; alfabetização e as Tecnologias de Informação e Comunicação; alfabetização e humanidades e a educação artística na alfabetização. Estes temas têm total relação com a prática pedagógica nas escolas, pois constituem desafios enfrentados no cotidiano, e foram elencados a partir da própria necessidade, trazida pelos educadores em cursos de formação anteriores, de relacionar a formação à realidade das escolas e dos educandos. Assim, a discussão promovida no grupo problematizou tais temas e promoveu uma intervenção na realidade, no sentido da construção de novos conhecimentos e metodologias.

Em 2016, ano em que foi oferecido o curso, o trabalho aconteceu em encontros quinzenais com professores do PEJA (adaptados ao calendário letivo do Programa), pesquisadores da área de EJA (que atuaram como formadores), contabilizando um total de 64 horas. Neste curso, participaram cerca de 35 professores.

Os pesquisadores/formadores da área de EJA que assumiram a tarefa de dinamizar o curso são ou já foram professores do PEJA (alguns professores adjuntos da UERJ e outros externos), característica que garante aos mesmos um conhecimento profundo sobre o programa e suas especificidades. Assim, mais do que aulas, os encontros proporcionaram a troca e o diálogo sobre as vivências e o cotidiano das escolas de EJA, principalmente levando em consideração que "um dos traços da formação dos educadores de jovens e adultos tem de ser conhecer as especificidades do que é ser jovem, do que é ser adulto" (ARROYO, 2006, p. 22), dentre outras características apresentadas pelos sujeitos com os quais atuam. 
A relação entre ensino, pesquisa e extensão foi proporcionada pela aproximação entre a Universidade e a escola pública. $O$ papel da universidade na formação de educadores perpassa a pesquisa de alternativas pedagógicas, o resgate e $\mathrm{o}$ apoio à sistematização da prática, a divulgação de inovações, a formação continuada e a sua integração com a comunidade escolar para a elaboração de propostas conjuntas de aperfeiçoamento da educação.

A parceria com a Secretaria Municipal de Educação do Rio de Janeiro (SME/RJ), representada pela Gerência de Educação de Jovens e Adultos (GEJA), se deu no sentido da divulgação e inscrição dos professores no curso e também por meio do diálogo com a coordenação do projeto no sentido do alcance dos objetivos propostos.

Os cursistas foram avaliados ao longo do projeto, por meio da produção de textos, relatos, diálogos e relatórios no intuito de avaliar o andamento do curso, sua aprendizagem, conhecer o perfil das escolas participantes e observar as contribuições do curso para a prática pedagógica.

\section{Resultados e Discussão}

Ações na área da Educação de Jovens e Adultos são cada vez mais importantes, sob o ponto de vista da garantia do direito à educação para todos, independentemente da idade ou de qualquer outra diferença constituída pelos sujeitos sociais.

O curso de extensão garantiu aos envolvidos compreenderem e problematizarem os principais desafios impostos pela realidade atual para a área da alfabetização de jovens e adultos; vislumbrarem e promoverem possibilidades de atuação no campo a partir dos estudos promovidos pelo grupo; refletirem sobre a prática pedagógica na área sob a ótica da educação como direito de todos; promoverem a pesquisa de estudos e práticas atuais na área e produzirem novos conhecimentos sobre a alfabetização de jovens e adultos que levem à construção de novas práticas, no intuito de vencer os desafios impostos pela realidade. Nas palavras de Freire (2002, p. 14),

Pensar a prática enquanto a melhor maneira de aperfeiçoar a prática. Pensar a prática através de que se vai reconhecendo a teoria nela embutida. [...] Quero dizer o seguinte: simplesmente toda prática coloca a seus sujeitos, de um lado, sua programação, de outro, sua avaliação permanente. Programar e avaliar não são, contudo, momentos separados um à espera do outro. São momentos em permanentes relações.

Para Freire, é preciso analisar criticamente a prática educativa e esse exercício crítico deve ser constante, permanente. $\mathrm{O}$ projeto proporcionou que educadores refletissem sobre sua prática pedagógica nas escolas, com os alunos, a partir dos temas trabalhados e debatidos junto ao grupo constituído. Esses educadores repensaram questões sobre o ensino, a aprendizagem, a avaliação, o planejamento, as relações cotidianas, os desafios e os caminhos possíveis de transformação da realidade. E isso trouxe resultados significativos verificados nos relatos dos professores e dos estudantes participantes, que demonstraram uma mudança nas ações realizadas em sala de aula.

Este projeto foi ao encontro de uma necessidade dos professores, pesquisadores e estudantes envolvidos, de realizar uma formação para alfabetizadores, a partir de uma parceria entre a Universidade do Estado do Rio de Janeiro e a Gerência de Educação de Jovens e Adultos, que objetivasse contribuir para a ação pedagógica dos educadores. E também de um desejo de realizar uma formação continuada para professores da EJA, no campo da extensão universitária, com muita qualidade e compromisso de todos os educadores envolvidos na construção dessa proposta.

O projeto permitiu e incentivou também a presença dos estudantes de Pedagogia no grupo formado. Assim, deu condição aos futuros pedagogos de entrarem em contato com a realidade das escolas e dos professores da Educação de Jovens e Adultos. As trocas pedagógicas e os debates ocorridos garantiram que os estudantes já percebessem e se envolvessem com as questões práticas do cotidiano das escolas.

Ao final do curso de extensão, foi solicitada ao grupo uma avaliação do curso, em que os professores sintetizaram suas principais impressões a respeito da formação. Dentre os pontos abordados pelos professores, estão: a relevância das oficinas, em que os professores produziram atividades para seus alunos; a partilha de aprendizados, troca de ideias e a reflexão coletiva; o despertar do interesse para o retorno aos estudos e a pesquisa de novas metodologias de trabalho; a participação de professores de diferentes escolas, favorecendo a troca de experiências; o empenho dos formadores, o domínio dos temas abordados e o estímulo aos professores; a relação entre teoria e prática presente em todos os encontros do curso; a contribuição para a formação continuada dos educadores, entre outros aspectos.

Essas e outras impressões foram levadas em consideração no intuito de garantir essas experiências e proporcionar outras aos educadores envolvidos. Para tanto, os encontros, como espaço de troca, fomentaram a construção de novas experiências, conhecimentos e diálogos. De acordo com Soares (2001, p. 221): 
potencialização do sujeito nas suas diversas dimensões. Para que essa educação se concretize é preciso pensar o educador de EJA como um profissional em formação.

Nesse sentido, a formação continuada assume-se como um repensar de práticas e geração de novas leituras do mundo e da realidade, e não como um espaço burocrático, normativo e regulador da ação pedagógica. $\mathrm{O}$ curso de extensão trouxe à tona as dificuldades enfrentadas pelos educadores no processo de alfabetização, mas também seus sucessos e práticas bem-sucedidas na sala de aula.

\section{Conclusões}

Trabalhar com a formação de educadores da EJA e, mais especificamente, com os alfabetizadores requer uma análise política das condições em que se encontram as escolas atualmente. Assim, uma formação bem elaborada será capaz de fornecer subsídios para essa análise crítica das condições sociais e materiais das escolas dentro do sistema.

Como a formação, para a maioria dos educadores, ocorre ao mesmo tempo em que se dá a atuação em sala de aula, como formação continuada e não formação inicial, seus saberes profissionais se constituem no próprio contexto de ação (DI PIERRO; VÓVIO; ANDRADE, 2008). Assim, os cursos são espaços privilegiados de trocas, aprendizagens, construção de planejamentos etc. Por isso, não podem ter um caráter prescritivo e regulador da prática, mas necessitam fomentar a busca, além das relações didáticas tradicionais, de estudos, pesquisas e outras práticas para o aprimoramento da ação educativa (FÁVERO; RUMMERT; DE VARGAS, 1999).

O curso de extensão torna-se, assim, um momento em que os educadores expõem os principais desafios enfrentados no cotidiano, seus anseios e angústias sobre a aprendizagem de seus educandos. Mas também representa um espaço em que são suscitadas reflexões, autoavaliações e construção de saberes.

Como a EJA é também o espaço da diversidade (etária, religiosa, étnica, cultural, de gênero etc.), os conteúdos abordados necessitam trazer essa diversidade para o debate e a reflexão. Por isso, no curso, os professores discutiram as especificidades dos sujeitos atendidos, suas necessidades de aprendizagem, reconhecendo-os como sujeitos de direitos.

Assim, conclui-se que pôr o foco na formação continuada de alfabetizadores da EJA vai ao encontro de uma necessidade atual, pois possibilita o repensar de práticas pedagógicas que dialogam com a realidade vivenciada nas escolas e nas salas de aula, conduzido por um olhar crítico e criativo sobre os educandos e o processo de ensino e de aprendizagem. Ainda que sejam inúmeros os desafios impostos pela realidade, eles necessitam ser problematizados e tensionados pelos educadores envolvidos na modalidade. Um curso de extensão dessa natureza mostra-se como um espaço essencial para essa reflexão.

\section{Referências}

ARROYO, Miguel G. Formar educadoras e educadores de jovens e adultos. In: SOARES, Leôncio. (Org.). Formação de Educadores de Jovens e Adultos. Belo Horizonte: Autêntica/Secad-Mec/Unesco, 2006.

DI PIERRO, Maria Clara. Notas sobre a redefinição da identidade e das políticas públicas de educação de jovens e adultos no Brasil. Educação e Sociedade. Campinas, v. 26, n. 92 , out. 2005 .

VÓVIO, Cláudia Lemos; ANDRADE, Eliane Ribeiro. Alfabetização de jovens e adultos no Brasil: lições da prática. Brasília: UNESCO, 2008.

FÁVERO, Osmar; RUMMERT, Sonia Maria; DE VARGAS, Sonia Maria. Formação de profissionais para a educação de jovens e adultos trabalhadores. Educação em Revista, Belo Horizonte, n. 30, dez. 1999.

FREIRE, Paulo. Pedagogia do Oprimido. 17.ed. Rio de Janeiro: Paz e Terra, 1987.

Pedagogia da autonomia: saberes necessários à prática educativa. 7.ed. São Paulo: Paz e Terra, 1998.

Professora sim, tia não: cartas a quem ousa ensinar. 2.ed. São Paulo: Olho d'Âgua, 2002.

HADDAD, Sérgio; DI PIERRO, Maria Clara. Escolarização de jovens e adultos. Revista Brasileira de Educação. São Paulo, n. 14, p. 108-130, mai./ago. 2000a.

Aprendizagem de jovens e adultos: avaliação da décàda da educação para todos. São Paulo em Perspectiva, São Paulo, v.14, n.1, p. 29-40, mar., 2000 b.

IBGE. Pesquisa Nacional por Amostra de Domicílios (PNAD) 2013. Disponível em: http://www.ibge.gov.br. Acesso em: 09 mai. 2016.

SOARES, Leôncio José Gomes. As políticas de EJA e as necessidades de aprendizagem dos jovens e adultos. In: RIBEIRO, Vera Masagão (Org.). Educação de jovens e adultos: novos leitores, novas leituras. Campinas, SP: Mercado de Letras: Associacão de Leitura do Brasil - ALB; São Paulo: Ação Educativa, 2001.

Avanços e desafios na formação do educador de jovens e adultos. In: MACHADO, Maria Margarida (Org.). Formação de educadores de jovens e adultos. Brasília: Secad/MEC, Unesco, 2008.

SOARES, Magda. Letramento e alfabetizacão: as muitas facetas. Revista Brasileira de Educação, São Paulo, n. 25, 2004.

VÓVIO, Cláudia Lemos. Alfabetização de pessoas jovens e adultos: outras miradas, novos focos de atenção. In: SAMPAIO, Marisa Narciso; ALMEIDA, Rosilene Souza (Orgs.). Práticas de Educação de Jovens e Adultos: complexidades, desafios e propostas. Belo Horizonte: Autêntica, 2009

ZANETTI, Maria Aparecida. Reflexões sobre a formação de educadores de jovens e adultos em redes de ensino públicas. In: MACHADO, Maria Margarida. (Org.). Formacão de educadores de jovens e adultos. Brasília: Secad/MEC, Unesco, 2008. 